\title{
Training Evaluation of Vocational Qualification for the Skilled Talents Based on AHP
}

\author{
Tiegang $\mathrm{Li}^{1, \mathrm{a}}$, Chen Zhan ${ }^{2, \mathrm{~b}}$ \\ ${ }^{1}$ Mechanical School, Shenyang Institute of Engineering, Shenyang, 110036, China \\ ${ }^{2}$ Mechanical School, Shenyang Institute of Engineering, Shenyang, 110036, China \\ aemail: Itgchina@126.com, bemail: neuldm@126.com
}

Keywords: Skilled talent; training evaluation; Analytic Hierarchy Process (AHP); Fuzzy Evaluation

\begin{abstract}
Aiming at uncertainty and complexity of training evaluation in vocational qualification for the skilled talents, the paper introduced a index system that applied The Analytic Hierarchy Process (AHP) to establish the evaluation model, the problem of construction, weight selection and satisfying consistency of judgment matrix is discussed. By means of the examples the students' ability are evaluated, meanwhile the feasibility of the proposed method applying process decision making is verified.
\end{abstract}

\section{Introduction}

Skilled talent refers to the front line in the field of production and service, mastering of expertise and technology, with superb operational skills, and in practice can solve key technical and process operational problems of personnel. Skilled talent, including skilled workers in the professional qualifications of technicians and senior technicians, mainly located in the first, second and tertiary industries in the high-skilled jobs, is an important part of our talent and the industry's Outstanding representatives [1].

Vocational qualification is a basic requirement for the knowledge, skills and abilities necessary to engage in a profession. Vocational qualification certificate is the national recognition of the applicant's professional (type of work) knowledge, technology, ability, which is the main basis for job, service, independent business and unit recruitment, also is an important content of the labor employment system. Vocational qualification is also a strategic measurement for the development of human resources in China, which is a special government examination, and it is also an internationally recognized qualification system for technical personnel.

Application-oriented undergraduate colleges and higher vocational schools bear the important task of cultivating skilled talents, and how to evaluate their abilities according to the standards of vocational qualification certificates has important guiding significance.

This paper constructs the ability evaluation index system by combining with the training evaluation of the vocational qualification certificate of the skilled talents, and establishes the evaluation model of the technical talents by using Analytic Hierarchy Process (AHP), and verifies the feasibility of the method through concrete examples[2].

\section{Training Evaluation Index System}

The vocational skills examination can reflect the comprehensive technical ability of the operator and reform the evaluation mechanism in the existing evaluation system. According to the national examination and training standard of vocational skill appraisal, the evaluation system of vocational skills training should be established with the target layer, the criteria layer and the index layer[3] .

There are lots of factors affecting Professional qualification training Practical evaluation. Generally, the main factors include factors of the technique, operation performance and professional accomplishment. The AHP method made by Satty is suitable for solving issues of general assessment with multiple targets and principles. The hierarchy structure of assessment in CNC milling examination is made per figure 1. 


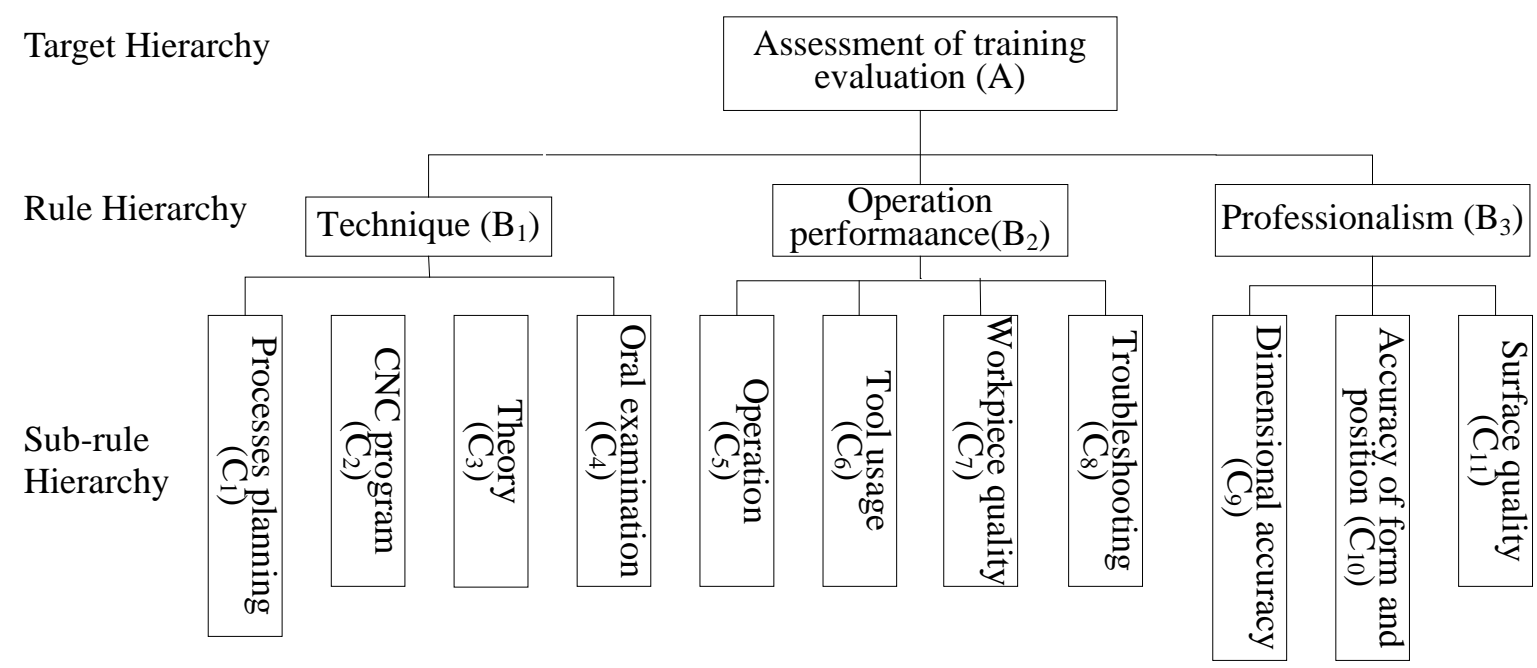

Fig.1. Hierarchy model of Professional qualification training Practical evaluation

\section{Ability Evaluation Based on AHP}

Comparing the index factors of the same layer, the judgment matrix of each layer is constructed by using the proportional scale of Table 1[4] [5].

Table 1. Scale of relative importance

\begin{tabular}{|c|c|}
\hline Scale $\left(a_{i j}\right)$ & Definition \\
\hline 1 & $i$ is as important as $j$ slightly \\
\hline 3 & $i$ is more important than $j$ a little \\
\hline 5 & $i$ is more important than $j$ obviously \\
\hline 9 & $i$ is more important than $j$ thoroughly \\
\hline $2,4,6,8$ & $i$ is more important than $j$ wondrously \\
\hline $\begin{array}{c}\text { the reciprocal of } \\
\text { the above values }\end{array}$ & the medians of above judgment \\
\hline
\end{tabular}

After compared the significance level of each evaluating criteria (in table 1), estimation matrix has formed:

$$
A=\left[\begin{array}{lllc}
a_{11} & a_{12} & \ldots & a_{1 n} \\
a_{21} & a_{22} & \ldots & a_{2 n} \\
\ldots & \ldots & \ldots & \ldots \\
a_{n 1} & a_{n 2} & \ldots & a_{n n}
\end{array}\right]
$$

Where $a_{i j}>0, a_{i j}=\frac{1}{a_{j i}}, a_{i i}=1 \quad i, j=1,2, \ldots, n$.

$$
\begin{aligned}
& W_{i}=\sqrt[n]{\left(\prod_{j=1}^{n} a_{i j}\right)} \\
& W_{i}^{0}=W_{i} /\left(\sum_{j=1}^{n} W_{j}\right) \\
& \lambda_{\max }=\frac{1}{n} \sum_{i=1}^{n} \lambda_{i} \\
& \lambda_{i}=\left(\sum_{j=1}^{n} a_{i j} W_{j}\right) / W_{i}
\end{aligned}
$$

Where $W$ is the characteristic vector of estimation matrix, $\lambda_{\max }$ is the maximum characteristic root of the estimation matrix, $n$ is the rank of estimation matrix. 
Table 2. RI parameter

\begin{tabular}{|c|c|c|c|c|c|c|c|c|}
\hline Rank & 3 & 4 & 5 & 6 & 7 & 8 & 9 & 10 \\
\hline RI & 0.52 & 0.89 & 1.11 & 1.25 & 1.35 & 1.40 & 1.45 & 1.49 \\
\hline
\end{tabular}

The rate of random consistence can be obtained as:

$$
\begin{aligned}
& C R=C I / R I \\
& C I=\left(\lambda_{\max }-n\right) /(n-1)
\end{aligned}
$$

Where $C I$ is the consistent index, $R I$ is the index of average random coincidence in table 2.

When $C R \leqslant 0.1$, the estimation matrix has satisfied consistence. If not, modification is needed.

The set of evaluation factor is $\mathrm{A}=\{\mathrm{A} 1, \mathrm{~A} 2, \ldots, \mathrm{Am}\}$, the evaluation set is $\mathrm{V}=\{\mathrm{v} 1, \mathrm{v} 2, \ldots, \mathrm{vn}\}$, Aiw is the Judgment object influence factor, vi is the object To be evaluated, $R: A \times V \rightarrow[0,1], \widetilde{R}=\left(r_{i j}\right)_{m \times n}$, the weigh of assessment is $\widetilde{W}=\left(w_{1}, w_{2}, \ldots, w_{m}\right)$, Fuzzy comprehensive evaluation set is as shows:

$$
\widetilde{Y}=\tilde{W} \oplus \widetilde{R}=\left(w_{i}\right)_{m} \oplus\left(r_{i j}\right)_{m \times n}=\left(y_{1}, y_{2}, \ldots, y_{n}\right)
$$

The evaluation index can be divided into two categories: quantitative index and qualitative index. The qualitative index is scaled by proportional method. First, the evaluation index is divided into grades, and then the $\mathrm{n}$ experts are judged. Finally, the frequency belongs to each grade as the membership degree.

For the quantitative indicators using the membership function to determine membership, the dimensions of the indicators are not uniform or non-quantitative, there is no comparable, we must establish a unified measurement scale. The maximum-minimum method was adopted to determine the membership degree of each index:

$$
\mu_{\tilde{R} i}\left(v_{i}\right)=r_{i}= \begin{cases}0 & v_{i} \in\left[0, v_{\min , i}\right] \\ \frac{v_{i}-v_{\min , i}}{v_{\max , i}-v_{\min , i}} & v_{i} \in\left[v_{\min , i}, v_{\max , i}\right] \\ 1 & \text { Others }\end{cases}
$$

\section{Test results}

The expert decide the weights for each objective with integral-valued 1-9 scale, the matrix are formed as follows in table 3 and table 4 .

Table 3. Estimation matrixes and calculated parameters at all levels

\begin{tabular}{|c|c|c|c|c|c|c|c|}
\hline $\mathrm{A}$ & $\mathrm{B}_{1}$ & $\mathrm{~B}_{2}$ & $\mathrm{~B}_{3}$ & $\mathrm{~W}_{\mathrm{i}}$ & $\mathrm{W}_{\mathrm{i}}{ }^{0}$ & $\lambda_{\mathrm{i}}$ & $\lambda_{\max }=3.054$ \\
\hline $\mathrm{B}_{1}$ & 1 & 2 & 2 & 1.587 & 0.493 & 3.054 & $\mathrm{CI}=0.027$ \\
\hline $\mathrm{B}_{2}$ & 0.5 & 1 & 2 & 1 & 0.311 & 3.054 & $\mathrm{RI}=0.52$ \\
\hline $\mathrm{B}_{3}$ & 0.5 & 0.5 & 1 & 0.63 & 0.196 & 3.053 & $\mathrm{CR}=0.052$ \\
\hline
\end{tabular}

a)

\begin{tabular}{|c|c|c|c|c|c|c|c|c|}
\hline $\mathrm{B}_{1}$ & $\mathrm{C}_{1}$ & $\mathrm{C}_{2}$ & $\mathrm{C}_{3}$ & $\mathrm{C}_{4}$ & $\mathrm{~W}_{\mathrm{i}}$ & $\mathrm{W}_{\mathrm{i}}{ }^{0}$ & $\lambda_{\mathrm{i}}$ & $\lambda$ \\
\hline $\mathrm{C}_{1}$ & 1 & 5 & 6 & 7 & 3.807 & 0.631 & 4.27 & $\mathrm{CI}=0.074$ \\
\hline $\mathrm{C}_{2}$ & 0.2 & 1 & 3 & 4 & 1.245 & 0.206 & 4.24 & $\mathrm{RI}=0.89$ \\
\hline $\mathrm{C}_{3}$ & 0.167 & 0.333 & 1 & 3 & 0.651 & 0.108 & 4.13 & $\mathrm{CR}=0.083$ \\
\hline $\mathrm{C}_{4}$ & 0.143 & 0.25 & 0.333 & 1 & 0.331 & 0.055 & 4.24 & \\
\hline
\end{tabular}

b)

\begin{tabular}{|c|c|c|c|c|c|c|c|c|}
\hline $\mathrm{B}_{2}$ & $\mathrm{C}_{5}$ & $\mathrm{C}_{6}$ & $\mathrm{C}_{7}$ & $\mathrm{C}_{8}$ & $\mathrm{~W}_{\mathrm{i}}$ & $\mathrm{W}_{\mathrm{i}}{ }^{0}$ & $\lambda_{\mathrm{i}}$ & $\lambda$ \\
\hline $\mathrm{C}_{5}$ & 1 & 3 & 5 & 9 & 3.409 & 0.605 & 4.007 & $\mathrm{CI}=0$ \\
\hline $\mathrm{C}_{6}$ & 0.333 & 1 & 2 & 3 & 1.189 & 0.211 & 4.016 & $\mathrm{RI}=0.89$ \\
\hline $\mathrm{C}_{7}$ & 0.2 & 0.5 & 1 & 2 & 0.669 & 0.119 & 4.016 & $\mathrm{CR}=0$ \\
\hline $\mathrm{C}_{8}$ & 0.111 & 0.333 & 0.5 & 1 & 0.371 & 0.065 & 3.110 & \\
\hline
\end{tabular}

c) 
Table 4. Estimation matrixes and calculated parameters at all levels

\begin{tabular}{|c|c|c|c|c|c|c|c|}
\hline $\mathrm{B}_{3}$ & $\mathrm{C}_{9}$ & $\mathrm{C}_{10}$ & $\mathrm{C}_{11}$ & $\mathrm{~W}_{\mathrm{i}}$ & $\mathrm{W}_{\mathrm{i}}{ }^{0}$ & $\lambda_{\mathrm{i}}$ & $\lambda_{\max }=3$ \\
\hline $\mathrm{C}_{9}$ & 1 & 2 & 2 & 1.587 & 0.5 & 3 & $\mathrm{CI}=0$ \\
\hline $\mathrm{C}_{10}$ & 0.5 & 1 & 1 & 0.794 & 0.225 & 3 & $\mathrm{RI}=0.52$ \\
\hline $\mathrm{C}_{11}$ & 0.5 & 1 & 1 & 0.794 & 0.225 & 3 & $\mathrm{CR}=0$ \\
\hline
\end{tabular}

a)

\begin{tabular}{|c|c|c|c|c|c|c|}
\hline & $\mathrm{B}_{1}$ & $\mathrm{~B}_{2}$ & $\mathrm{~B}_{3}$ & \multirow{2}{*}{$\mathrm{CI}_{\mathrm{T}}$} & \multirow{2}{*}{$\mathrm{CR}_{\mathrm{T}}$} & \multirow{2}{*}{$W_{i}$} \\
\hline & 0.493 & 0.311 & 0.196 & & & \\
\hline $\mathrm{C}_{1}$ & 0.631 & & & \multirow{4}{*}{0.074} & \multirow{4}{*}{0.083} & 0.311 \\
\hline $\mathrm{C}_{2}$ & 0.206 & & & & & 0.102 \\
\hline $\mathrm{C}_{3}$ & 0.108 & & & & & 0.053 \\
\hline $\mathrm{C}_{4}$ & 0.055 & & & & & 0.027 \\
\hline $\mathrm{C}_{5}$ & & 0.605 & & \multirow{4}{*}{0} & \multirow{4}{*}{0} & 0.188 \\
\hline $\mathrm{C}_{6}$ & & 0.211 & & & & 0.066 \\
\hline $\mathrm{C}_{7}$ & & 0.119 & & & & 0.037 \\
\hline $\mathrm{C}_{8}$ & & 0.065 & & & & 0.020 \\
\hline $\mathrm{C}_{9}$ & & & 0.5 & \multirow{3}{*}{0} & \multirow{3}{*}{0} & 0.098 \\
\hline $\mathrm{C}_{10}$ & & & 0.225 & & & 0.044 \\
\hline $\mathrm{C}_{11}$ & & & 0.225 & & & 0.044 \\
\hline
\end{tabular}

b)

The weight $w$ is:

$w=(0.311,0.102,0.053,0.027,0.188,0.066,0.037,0.020,0.098,0.044,0.044) \quad, \quad C I_{T}=0.036$, $R I_{T}=0.817, C R_{T}=0.044<0.1$, the estimation matrix has satisfied consistence.

The set of assessment $\mathrm{V}=$ (excellent, good, fine, poor), the excellent is $\mathrm{V} 1=[85,100]$, the good is $\mathrm{V} 2=[75,85)$, the average is $\mathrm{V} 3=[60,75)$, the poor is $\mathrm{V} 4=[0,60)$. The weight matrix of each index are shown as:

$$
\begin{aligned}
R_{1} & =\left(\begin{array}{cccc}
0 & 0.1 & 0.8 & 0 \\
0 & 0.3 & 0.6 & 0 \\
0 & 0.2 & 0.7 & 0 \\
0 & 0 & 0.7 & 0.2
\end{array}\right) \\
R_{2} & =\left(\begin{array}{cccc}
0 & 0.3 & 0.6 & 0 \\
0 & 0 & 0.8 & 0.1 \\
0 & 0.1 & 0.7 & 0.1 \\
0 & 0.1 & 0.6 & 0.2
\end{array}\right) \\
R_{3} & =\left(\begin{array}{llll}
0 & 0.2 & 0.7 & 0 \\
1 & 0.1 & 0.5 & 0.1 \\
0 & 0.2 & 0.6 & 0.1
\end{array}\right)
\end{aligned}
$$

9 experts on a student's assessment score are shown as in Table 5. 
Table 5. Expert evaluation data

\begin{tabular}{|c|c|c|c|c|c|}
\hline Value & excellent & good & average & poor & weight \\
\hline $\mathrm{C}_{1}$ & 0 & 1 & 8 & 0 & 0.311 \\
\hline $\mathrm{C}_{2}$ & 0 & 3 & 6 & 0 & 0.102 \\
\hline $\mathrm{C}_{3}$ & 0 & 2 & 7 & 0 & 0.053 \\
\hline $\mathrm{C}_{4}$ & 0 & 0 & 7 & 2 & 0.027 \\
\hline $\mathrm{C}_{5}$ & 0 & 3 & 6 & 0 & 0.188 \\
\hline $\mathrm{C}_{6}$ & 0 & 0 & 8 & 1 & 0.066 \\
\hline $\mathrm{C}_{7}$ & 0 & 1 & 7 & 1 & 0.037 \\
\hline $\mathrm{C}_{8}$ & 0 & 1 & 6 & 2 & 0.020 \\
\hline $\mathrm{C}_{9}$ & 0 & 2 & 7 & 0 & 0.098 \\
\hline $\mathrm{C}_{10}$ & 1 & 1 & 5 & 1 & 0.044 \\
\hline $\mathrm{C}_{11}$ & 0 & 2 & 6 & 1 & 0.044 \\
\hline 0
\end{tabular}

$$
\begin{aligned}
& B_{1}=W_{1} \times R_{1}=\left(\begin{array}{llll}
0 & 0.0723 & 0.366 & 0.0054
\end{array}\right), B_{2}=(0,0.0621,0.2035,0.0143), B_{3}=(0.044,0.0328,0.117,0.0088) . \\
& R=\left(\begin{array}{cccc}
0 & 0.0723 & 0.366 & 0.0054 \\
0 & 0.0621 & 0.2035 & 0.0143 \\
0.044 & 0.0328 & 0.117 & 0.0088
\end{array}\right)
\end{aligned}
$$

The assessment value $A=W \cdot R=(0.493,0.311,0.196) R=(0.008624,0.0613858,0.2666585,0.0088343)$, the simplified valve is $A=(0.02,0.18,0.77,0.03)$, from the point of result, the probability being excellent is 0.02 , expressed as a percentile: $A=95 \times 0.02+80 \times 0.18+70 \times 0.77+55 \times 0.03=71.85$, the result of assessment is average.

\section{Conclusion}

This paper establishes the model of vocational qualification evaluation of skilled talents, and combines qualitative analysis and quantitative analysis with AHP and fuzzy mathematics. It analyzes the evaluation of the ability index system and provides information for the teaching feedback of vocational skills training. Teaching reform provides a basis.

\section{Acknowledgement}

In this paper, the research was sponsored by the Education Commission Foundation of Liaoning Province (Project No. GJ13ZD05).

\section{References}

[1] Weimin Wang. Analysis on the Design Concept of National Vocational Education Qualification Framework in India [J]. Studies in Foreign Education, 2014, (2) 120-128.

[2] Zhengqing Luo, Shanlin Yang. Comparative Study on Several Scales in AHP [J]. Systems Engineering-theory \& practice, 2004 (9) 51-60.

[3] Hui Zhu. Study on Evaluation Index System of High Skilled Talents in Huabei Oilfield [D]. BaoDing: Hebei University, 2013.

[4] Baorong Qin,Wen ke,Ningsheng Wang. Decision-making Method of Machine Tool Selection Based on Fuzzy Comprehensive Evaluation [J]. China Mechanical Engineering, 2003, 14 (3) 216-219.

[5]Xiaoting Jin, The Evaluation Method of Resource - based Cultural Industry Competitiveness Based on AHP [J]. Statistics \& Decision, 2013, (10) 80-84. 